\title{
Fire frequency analysis in Portugal (1975-2005), using Landsat-based burnt area maps
}

\author{
Sofia L. J. Oliveira ${ }^{\mathrm{A}, \mathrm{C}}$, José M. C. Pereira ${ }^{\mathrm{A}}$ and João M. B. Carreiras ${ }^{\mathrm{B}}$ \\ A Forest Research Centre, School of Agriculture, Technical University of Lisbon, \\ Tapada da Ajuda, 1349-017 Lisbon, Portugal. \\ ${ }^{B}$ Geoinformation for Development Centre, Department of Natural Sciences, \\ Tropical Research Institute, R. Joao de Barros 27, 1300-319 Lisbon, Portugal. \\ ${ }^{\mathrm{C}}$ Corresponding author. Email address: sloliveira@isa.utl.pt
}

\begin{abstract}
Fire frequency in 21 forest planning regions of Portugal during the period 1975-2005 was estimated from historical burnt area maps generated with semi-automatic classification of Landsat Thematic Mapper (TM) satellite imagery. Fire return interval distributions were modelled with the Weibull function and the estimated parameters were used to calculate regional mean, median and modal fire return intervals, as well as regional hazard functions. Arrangement of the available data into three different time series allowed for assessment of the effects of minimum mapping unit, time series length and use of censored data on the Weibull function parameter estimates. Varying the minimum mapping unit between 5 and 35 ha had a negligible effect on parameter estimates, whereas changing the time series length from 22 to 31 years substantially affected the estimates. However, the strongest effect was caused by censored data. Its exclusion led to substantial overestimation of fire frequency and of burning probability dependence on fuel age. We estimated a countrywide mean fire interval of 36 years and an annual burnt area of $1.2 \%$. Regional variations in fire frequency descriptors were interpreted in terms of land cover and land use practices that affect the contemporary fire regime in Portugal.
\end{abstract}

Additional keywords: censored data, Weibull model.

Received 23 October 2010, accepted 24 April 2011, published online 24 October 2011

\section{Introduction}

Portugal is the smallest country in southern Europe but has the highest fire incidence in the region. The total burnt area from 1980 to 2005 was 2714547 ha, with a mean annual value of 108582 ha, or $1.18 \%$ of the total area of the country. For Spain, France, Italy and Greece, the mean annual percentages of burnt area during the same period were $0.37,0.05,0.39$ and $0.35 \%$ respectively (European Commission 2006). The Landsat-based national fire atlas developed at the Forest Research Centre (Technical University of Lisbon, Lisbon, Portugal), which provides the data for our analysis, revealed large interannual variability in burnt area, ranging from a maximum of 440000 ha in 2003 to a minimum of 15462 ha in 1977. The years 1985 and 2005 were also severe fire years, whereas 1988 and 1997 experienced low fire incidence. Pereira et al. (2005) and Trigo et al. (2006) showed climate to be a major driver behind these annual fluctuations in the extent of area burnt. Therefore, it is appropriate for the fire frequency analysis to encompass a time span in the range required to define a climatological normal (i.e. $\sim 30$ years). Spatial variability in fire incidence is also high (Pereira and Santos 2003; Pereira et al. 2006). With the exception of the flat, coastal region, the northern half of the country is much more fire prone than the southern half, owing to differences in land use and cover, topography, climate and population density. Therefore, fire frequency analyses require a regional approach to properly capture the geographical heterogeneity of fire regime.

Few fire frequency studies are available for the Mediterranean ecosystems of southern Europe. Vázquez and Moreno (2001) analysed a dataset of 75 forest fires that burnt a total of $58.13 \mathrm{~km}^{2}$ in a $14 \times 14-\mathrm{km}$ study area at Sierra de Gredos (Spain), during the period 1970-90, with fire maps derived from the interpretation of aerial photographs. The fire rotation period was calculated as 64 years. The study by Díaz-Delgado et al. (2004) is similar to our present work, in both spatial and temporal scope, as well as in methodological approach. DíazDelgado et al. (2004) analysed fire frequency in Catalonia (Spain), a region with an area of $32100 \mathrm{~km}^{2}$ between 1975 and 1998, using Landsat MultiSpectral Scanner (MSS) data. Fire rotation for the region was estimated as 133 years. Mean fire interval, hazard of burning, mortality and survivorship functions for vegetation patches were also estimated using the Weibull function.

In other Mediterranean regions of the world, Polakow and Dunne (1999) modelled the fire return interval in the Cape of Good Hope Nature Reserve $\left(75.5 \mathrm{~km}^{2}\right)$, South Africa, from 1934 to 1992 . They found that the probability of burning increased with time since fire and estimated a multi-century long fire 
cycle. Also in South Africa, Kraaij (2010) analysed the fire regime in Bontebok National Park, with $34.35 \mathrm{~km}^{2}$, from 1972 to 2009; the fire rotation period for the park was estimated at 7.2 years. In California shrublands, Moritz (2003) analysed the relationship between the hazard of burning and fuel age using the mapped fire history (1911-95) of southern and central California. His results indicated that shrublands exhibit a minimal degree of age dependency. Moritz et al. (2004) performed a fire frequency analysis of several hundred wildfires over California shrublands and showed there was no strong relationship between fuel age and fire probabilities. Moritz et al. (2009) reviewed and examined the issue of sampling decisions and censoring (i.e. incomplete observations) in fire interval data using a case study of a $1.1-\mathrm{km}^{2}$ fire occurred in southern California. It was concluded that inclusion and exclusion of censored data has the strongest effect on Weibull function parameter estimates. Fire frequency studies were also performed in regions experiencing Mediterranean climate in south-western Australia. O'Donnell et al. (2010) tested the effect of fuel age on fire interval length in an area of $15500 \mathrm{~km}^{2}$ of relatively undisturbed semi-arid shrubland and woodland from 1940 to 2007 . They observed that fire interval length and fuel age dependency vary with vegetation type and that probability of burning following a fire remains low for decades in all vegetation types.

The present study had two objectives: (i) a substantive objective, which was the characterisation of regional and national fire frequency patterns; and (ii) a methodological objective, which was to clarify the effect of some data series characteristics on fire frequency estimates. We used a 31-year time series of burnt area maps derived from Landsat satellite imagery for Portugal, the most fire prone country in southern Europe. Fire is the most important driver of land use and cover dynamics in Portugal and displays strong regional variation both in numbers of events and in area burnt. A further objective, the rigorous quantification of the frequency dimension of the contemporary fire regime in Portugal, is important for risk assessment, regional forest planning, biodiversity conservation and carbon sequestration assessment and management.

\section{Materials and methods}

Study area

We analysed fire frequency in mainland Portugal, a country located in south western Europe, between $37^{\circ} \mathrm{N}$ and $42^{\circ} \mathrm{N}$ latitude and $9.5^{\circ} \mathrm{W}$ and $6.5^{\circ} \mathrm{W}$ longitude and with an area of $88968 \mathrm{~km}^{2}$. A partitioning of Portugal into 21 forest planning regions (Santos et al. 2005), based on environmental attributes such as climate, topography, land cover and population density (Fig. 1) was used to perform the analysis at a regional level. Climate in Portugal is mostly Mediterranean, with hot, dry summers and cool, wet winters. Steep slopes and rugged topography are common and often covered by evergreen, drought resistant, pyrophytic vegetation. These environmental attributes render the region prone to vegetation fires, a feature that has been reinforced during the last 4-5 decades by demographic, socio-economic (Mather and Pereira 2006) and climatic trends (Pereira et al. 2002; Miranda et al. 2006). Many rural areas have experienced substantial population losses since the 1960s, leading to abandonment of agricultural fields and a reduction in goat and sheep herds, with a consequent decrease in grazing and diminished use of fuel wood. Therefore, woodlands, previously cleared of understorey, suffered progressive accumulation of fine fuels. Given the decrease in agricultural activity, many areas of marginal productivity were afforested or abandoned to natural secondary ecological succession, contributing to an increase in the area of forests and shrublands (Moreno 1999; Pausas and Vallejo 1999). These land use cover change processes have led to higher connectivity of high fuel loading vegetation patches, generating a landscape prone to large fires (Lepart and Debussche 1992).

Forests and woodlands cover about one-third of Portugal (Fig. 1). Maritime pine (Pinus pinaster) stands are located mainly in the northern half of the country. Blue gum (Eucalyptus globulus) plantations are abundant along the western half of Portugal and in a few interior areas in the central and southern parts of the country. Evergreen oak woodlands predominate in the southern half of Portugal. Cork oak (Quercus suber) woodlands are the main forest land cover type in south western Portugal and along the Tagus river valley, whereas holm oak (Quercus rotundifolia) predominates in the south east (Nunes et al. 2005). These woodlands are managed as agroforestry systems. Agricultural areas occupy about half of the study area and although present throughout the whole country, dominate in the central coastal plain, along main river valleys and in the southern half of the country. In central and northern Portugal, land ownership is very fragmented and the agricultural landscape is a fine grained mosaic of small parcels of diverse crops, vineyards and olive groves. The agricultural landscapes of southern Portugal are more extensive and homogeneous, dominated by dryland farming of cereal crops. Most areas of shrublands are found in eastern Portugal, but also occur in other parts of the country, usually in mountainous and sparsely populated regions.

\section{Burnt area mapping}

The present study involved analyses of the longest annual, country-wide fire atlas available in Europe, covering the period from 1975 to 2005 (Pereira and Santos 2003). The atlas has been derived from late summer-autumn Landsat satellite imagery, with a spatial resolution of $80 \mathrm{~m}$ and a minimum mapping unit of 35 ha for the period 1975-1983 (MultiSpectral Scanner (MSS) era). Since 1984 (Thematic Mapper (TM)-Enhanced Thematic Mapper (ETM) era) the spatial resolution of the data has been $30 \mathrm{~m}$ with a minimum mapping unit of 5 ha. Annual fire perimeter maps were derived with a semi-automatic procedure, starting with supervised image classification and complemented by thorough manual editing of classification results. Finally, burnt area estimates were compared against field statistics at the county level to detect and correct discrepancies. The fire atlas contains 34345 fire perimeters for the period of study (1975-2005), which accounts for a total burnt area of 3670000 ha and includes large interannual variability (Fig. 2). There is a marked increase in the number of fires recorded in 1984 and more recent years without a proportional increase in area burnt, essentially due to the use of higher spatial resolution imagery that allows for the detection of a much larger number of fire events. However, fires with sizes between 5 and 35 ha 


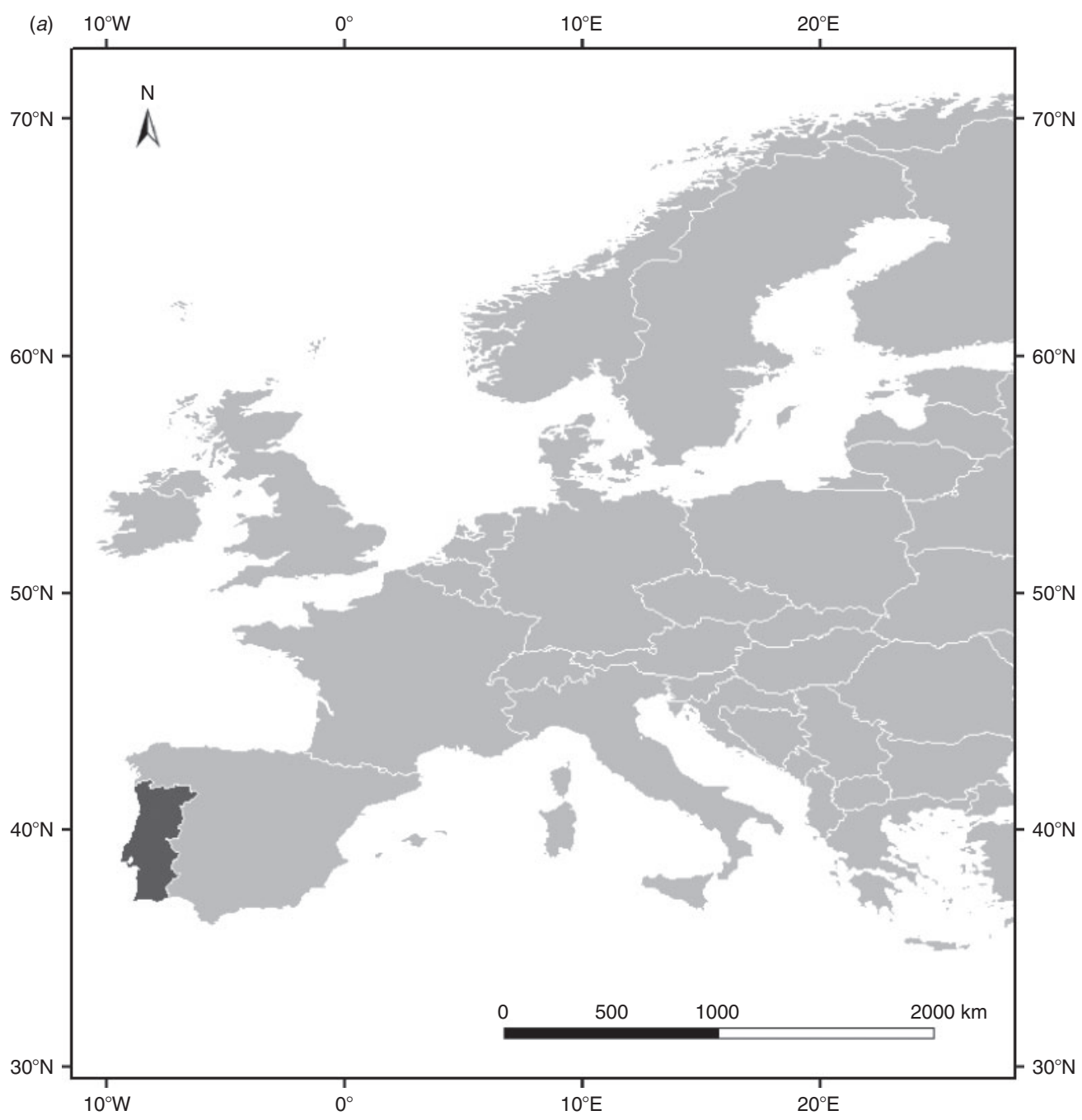

Fig. 1. (a) Location of Portugal in Europe and (b) CORINE 2006 land use and cover map (Caetano et al. 2009) with the regional divisions used in this study: AMI, Alto Minho; BMI, Baixo Minho; BAP, Barroso e Padrela; NDT, Nordeste; AMP, Área Metropolitana do Porto e Entre Douro e Vouga; TMG, Tâmega; DOU, Douro; CLI, Centro Litoral; DLA, Dão Lafões; BIN, Beira Interior Norte; PIN, Pinhal Interior Norte; PIS, Pinhal Interior Sul; BIS, Beira Interior Sul; OST, Oeste; RTJ, Ribatejo; AAL, Alto Alentejo; AML, Área Metropolitana de Lisboa; ACL, Alentejo Central; ALI, Alentejo Litoral; BAL, Baixo Alentejo; ALG, Algarve.

account for only a small proportion $(8.5 \%)$ of the total area burnt.

\section{Fire frequency analysis}

The fire atlas was used to create three time series: (1) fire perimeters $\geq 5$ ha for the period 1984-2005 (P8405 $\geq 5$ ); (2) fire perimeters $\geq 35$ ha for the period 1984-2005 (P8405 $\geq 35$ ); (3) fire perimeters $\geq 35$ ha for the period 1975-2005 (P7505 $\geq$ 35). The objective of constructing these time series was to assess the role of minimum mapping unit (series 1 and series 2) and time series length (series 2 and series 3 ) on the Weibull function parameters estimates. We also tested the effect of using complete $(\mathrm{C})$ fire intervals versus using both complete and singlecensored $(\mathrm{C}+\mathrm{CS})$ fire intervals on parameter estimates. Complete fire intervals were those for which both the start and end date of the fire free period were known. Single-censored fire intervals were those for which one of those dates was unknown. Ignoring single-censored data is likely to lead to incorrect fire frequency estimates (Polakow and Dunne 1999; Oliveira 2008; Moritz et al. 2009).

Fire frequency analysis estimates the probability distribution of vegetation survival or mortality from fire in a population of non-overlapping landscape units (Johnson and Gutsell 1994), that is, it quantifies how often fires burn in a particular area. Fire frequency studies are generally performed to estimate one of two related distributions: time-since-fire (survivorship) and fire interval (mortality). Other ways of quantifying spatio-temporal fire patterns are the fire rotation period (Heinselman 1973), the annual percentage of area burnt, the mean, median and modal fire intervals (Grissino-Mayer 1999). 


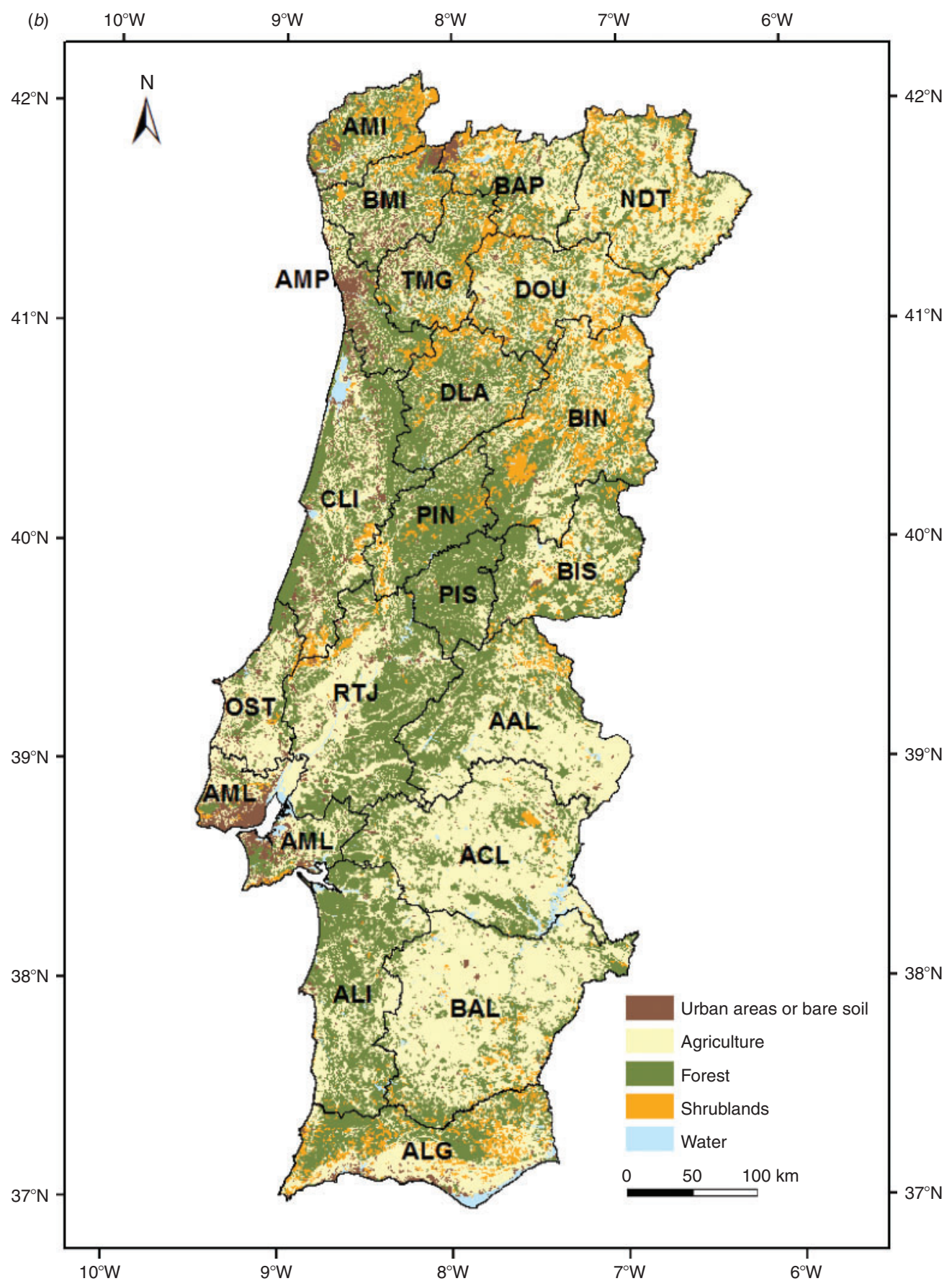

Fig. 1. (Continued)

\section{Fire rotation period}

A simple method used to calculate the fire rotation period (FRP), i.e. the length of time needed to burn an area of an extent equivalent to that of the study region, was proposed by Heinselman (1973) and used by Agee (1993) and Heyerdahl and Agee (1996). It is estimated by

$$
\mathrm{FRP}=(N \times S) / A
$$

where $N$ is the number of years of the study period; $A$ is the total area burnt (ha); and $S$ is the size of the study area (ha). An important advantage of this method, in addition to its simplicity, is that it does not depend on any fire frequency model, so requires no assumptions concerning stationarity of process or homogeneity of spatio-temporal regions. However, the fire rotation period method has some drawbacks, because it does require accurate determination of burnt area. Also, the lack of a 


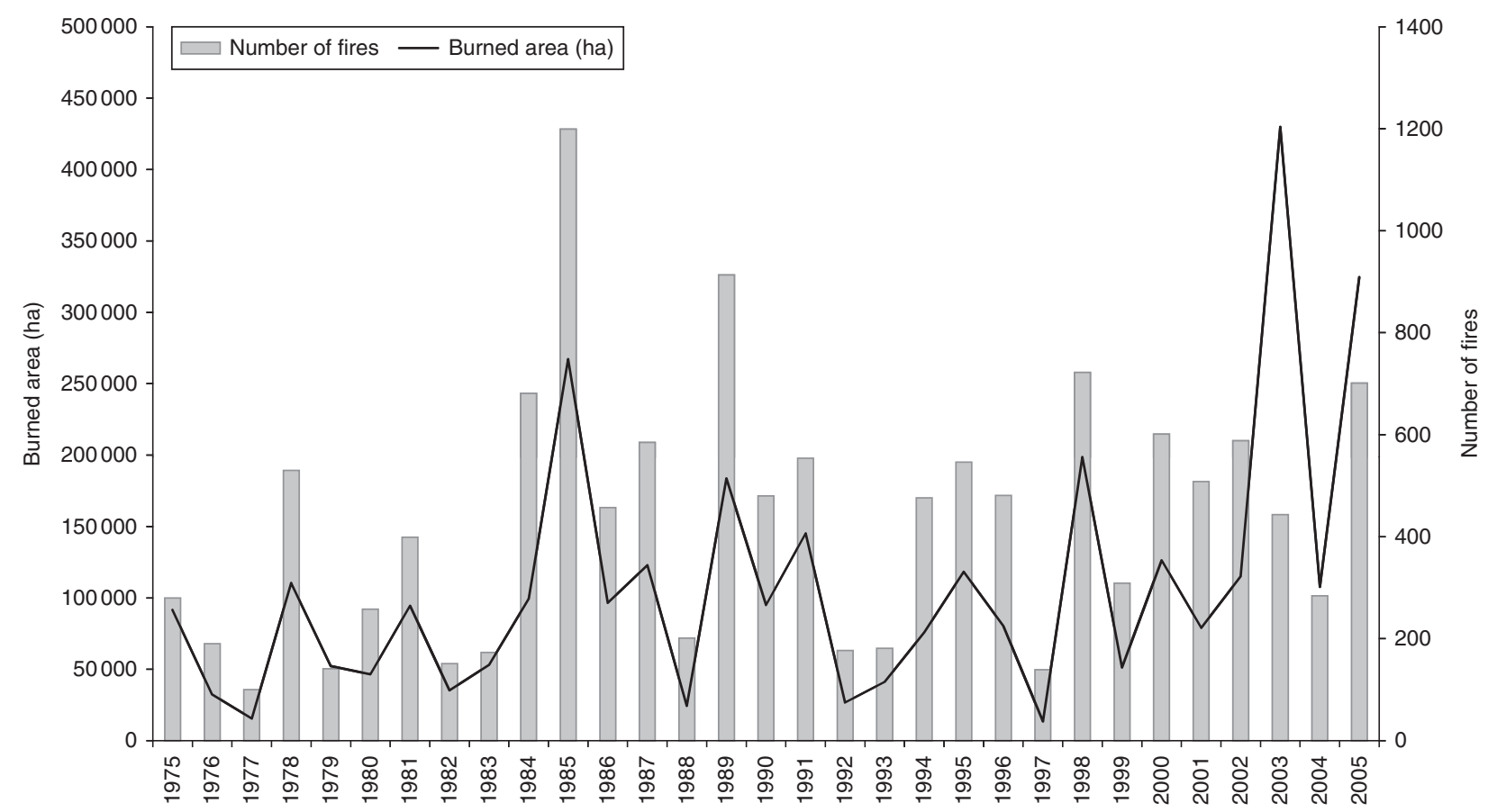

Fig. 2. Number of fires (grey) and burnt area (black) in mainland Portugal between 1975 and 2005.

formal statistical model renders hypothesis testing difficult (Díaz-Delgado et al. 2004).

The reciprocal of the fire rotation period is the annual percentage of area burnt (APAB), defined as the average proportion of the study area burnt each year,

$$
\mathrm{APAB}=\frac{1}{F R P}
$$

\section{The Weibull function}

Fire is a stochastic process, i.e. the actual occurrence of fire is a probabilistic event (Polakow and Dunne 1999). Thus, fire frequency can be described by a set of statistical models that describe the probability of fire. In fire frequency studies, the Weibull distribution has been widely used because of its flexibility, ability to model a range of positively skewed distributions and for better fitting fire history data than most alternatives (Johnson 1992; Polakow and Dunne 1999). McCarthy et al. (2001) considered that there was little a priori biological justification to use the Weibull function for analysing fire frequency and that its choice by several authors was essentially due to mathematical convenience. One of their criticisms of the Weibull function is that it cannot model delays in hazard of burning (the instantaneous potential that vegetation will burn during a specific time period) increase, or cases in which hazard of burning behaves asymptotically with time. Concerning the last issue, McCarthy et al. (2001) recognised that the Weibull distribution is capable of yielding reasonable fire interval distributions if most fires occur before the hazard of burning (approximated by fuel age) is unduly large. They propose various alternative functions for modelling fire frequency, but use of the Weibull model has remained the standard approach in subsequent studies (Moritz 2003; Moritz et al. 2004, 2009; O'Donnell et al. 2010). Abaimov et al. (2007) and Turcotte et al. (2007) analysed natural hazards, including wildfires, that exhibit self organisation and, consequently, display scaling laws in their frequency-magnitude distributions and return-time distributions. The latter are well approximated by the Weibull model because it is the only distribution that has a power law (i.e. scale invariant) hazard function. Considering this physical justification and for the sake of comparison with previous studies, we opted for using the Weibull model for fire frequency analyses.

The Weibull model for fire frequency data can be characterised by any one of the following functions: cumulative mortality distribution, $F(t)$ (distribution function), time since fire distribution, $A(t)$ (survival function), fire interval distribution, $f(t)$ (probability density function) and hazard of burning distribution, $\lambda(t)$ (hazard function):

$$
\begin{gathered}
F(t)=1-\exp \left[-\left(\frac{t}{b}\right)^{c}\right] \\
A(t)=1-F(t)=\exp \left[-\left(\frac{t}{b}\right)^{c}\right] \\
f(t)=\frac{c t^{c-1}}{b^{c}} \exp \left[-\left(\frac{t}{b}\right)^{c}\right] \\
\lambda(t)=\frac{c t^{c-1}}{b^{c}}
\end{gathered}
$$


It is also characterised by three parameters: a scale parameter $(b)$, a shape parameter $(c)$ and a shift location parameter $(\varepsilon)$ that is assumed to be zero in fire frequency analyses (Polakow and Dunne 1999). For a detailed review of the topic see Johnson and Gutsell (1994) and Dodson (2006).

The Weibull model assumes that hazard of burning is dependent on vegetation patch age. Parameter $c$ is dimensionless. Values of $c<1$ imply a decreasing likelihood of burning as the vegetation gets older; $c=1$ when hazard of burning is independent of age, whereas $c>1$ reflects an increasing likelihood of burning with vegetation age, with higher values of $c$ indicating higher degrees of burning probability dependence on age. Parameter $b$ has the dimensions of time and is known as the characteristic life (i.e. $63.2 \%$, or $1-1 / e$, of vegetation patches will have burnt by that age, regardless of the value of $c$ ). Polakow and Dunne (1999) give the form of the maximum likelihood function required for estimating the parameters $c$ and $b$, either for (i) complete fire return intervals (C) and (ii) complete and single-censored fire return intervals $(\mathrm{C}+\mathrm{SC})$. In the present study this function was adapted so that each fire return interval was weighted by the burnt area. In most previous studies confidence intervals for parameter estimates were not calculated or were obtained with non-parametric techniques. We also used a maximum likelihood approach to estimate the confidence intervals for parameters $c$ and $b$ (Dodson 2006).

The mean fire interval and the median fire interval represent the mean and median time intervals between fires at any location in the study area. The modal fire interval is the interval that contributes the greatest amount of area under the probability density function, representing the theoretical mode in a frequency distribution. These descriptors of central tendency were calculated as follows:

$$
\begin{gathered}
\text { mean fire interval }=b \Gamma\left(\frac{1}{c}+1\right) \\
\text { median fire interval }=b(\ln 2)^{1 / c} \\
\text { modal fire interval }=b((c-1) / c)^{1 / c}
\end{gathered}
$$

where $\Gamma$ is the gamma function and $c>1$.

\section{Results}

\section{Weibull function parameter estimates}

Weibull function parameter estimates used to calculate the mean, median and modal fire intervals are available in the Appendix. The size of the minimum mapping unit does not appear to have a statistically significant effect on the fire return intervals, regardless of the use of $\mathrm{C}$ or $\mathrm{C}+\mathrm{SC}$ intervals (Fig. $3 a-$ $f$ ). The longer time series yields significantly higher estimates of mean and median fire intervals than those obtained with the shorter series and this effect is more pronounced when using $\mathrm{C}+\mathrm{CS}$ data (Fig. $3 g-l$ ). Modal fire interval estimates do not differ greatly for $\mathrm{C}$ data but were significantly smaller for $\mathrm{C}$ $+\mathrm{SC}$ intervals than for $\mathrm{C}$ intervals. The largest differences in the fire return intervals arose as a result of using $\mathrm{C} v . \mathrm{C}+\mathrm{SC}$ data (Fig. $3 m-u$ ). Mean and median fire intervals estimates were always higher with $\mathrm{C}+\mathrm{SC}$ data than with $\mathrm{C}$ data only, regardless of minimum mapping unit and time series length. Inclusion of SC data in the analysis increased estimates of mean and median fire intervals at least 3-fold for the shorter time series, for both minimum mapping unit sizes. The increase was approximately 4-fold for the longer time series. The increase in mean fire interval estimates was particularly remarkable (57-61-fold) for the ACL (Alentejo Central) and BAL (Baixo Alentejo) regions, those that also display the lowest fire incidence. As minimum mapping unit size was found not to affect Weibull function parameter estimates, whereas series length and inclusion of SC data have a strong effect on those estimates, time series $\mathrm{P} 7505 \geq 35$ with $\mathrm{C}+\mathrm{SC}$ data was selected as the basis for subsequent analysis of fire frequency geographical patterns.

\section{Area burnt and fire rotation period}

Over the period 1975-2005 the total burnt area was 3353515 ha, which is equivalent to $38 \%$ of the study area. Time series $P 8405 \geq 5$ (with 32123 fires and 3133458 ha of burnt area) contains almost three times as many observations as series P8405 $\geq 35$ (11226 fires and 2822325 ha burnt), but only $10 \%$ more area burnt. Time series P7505 $\geq 35$ (13 448 fires and 3353515 ha burnt) has 17\% more fires and 16\% more burnt area than series $\mathrm{P} 8405 \geq 35$. Fire recurrence analysis showed that $60 \%$ of the total area affected by fire burnt only once, $23 \%$ burnt twice and $17 \%$ burnt three or more times. The majority of the burnt area was located in the northern half of the country, with the exception of ALG (Algarve) region, in the south. The region with the largest burnt area was BIN (Beira Interior Norte) followed by Douro (DOU), Dão Lafões (DLA), Pinhal Interior (PIN), Tâmega (TMG) and Barroso e Padrela (BAP).

The estimated fire rotation period for Portugal was 82 years (Table 1). The reciprocal value, 0.012 , is the mean annual percent of area burnt (1.2\%), at the national level. Values of the annual percentage of area burnt $>2 \%$ are found in central and northern Portugal. The BIN, PIN and PIS (Pinhal Interior Sul) regions had the highest observed values of annual percentage of area burnt (greater than 3\%), whereas BAL, ACL, ALI (Alentejo Litoral), AML (Área Metropolitana de Lisboa) and OST (Oeste) displayed the lowest values.

\section{Spatial and temporal patterns of fire frequency}

The fire interval distribution, $f(t)$, for Portugal showed that the modal fire interval was $\sim 7$ years. The mean and median fire return intervals were 36 and 27.6 years respectively. Regions AMI (Alto Minho), TMG, DLA and BIN displayed mean and median fire intervals shorter than 25 years and modal fire intervals shorter than 10 years (Fig. 4). The regions that displayed longer fire recurrence were BIS (Beira Interior Sul), AAL (Alto Alentejo), AML, ALI and BAL, with mean and median fire intervals longer than 50 years and modal fire intervals longer than 10 years. All shorter fire interval regions were located in the northern half of Portugal, whereas all longer interval regions, except for BIS, were located in the southern half of the country.

Confidence intervals at $95 \%$ for parameter $c$ estimates were generally very narrow, with the exceptions of OST $(1.47,1.63)$, BAL $(0.98,1.11)$, ACL $(0.96,1.06)$ and ALI $(1.66,1.90)$. At $\mathrm{ACL}$ and BAL the lower limit of the confidence interval for $c$ estimates is lower than 1 , implying burning probability was 

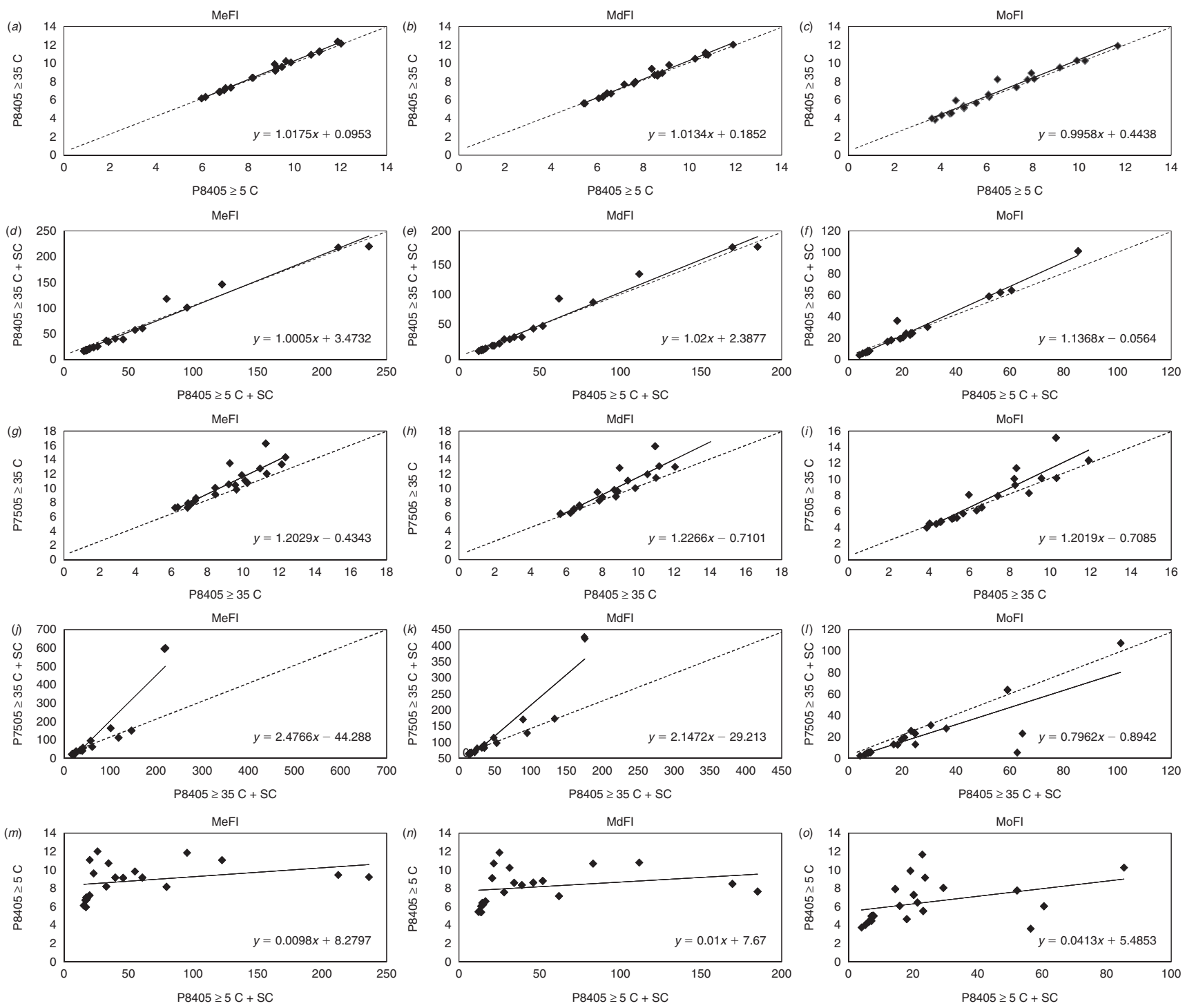

$\mathrm{MeF}$
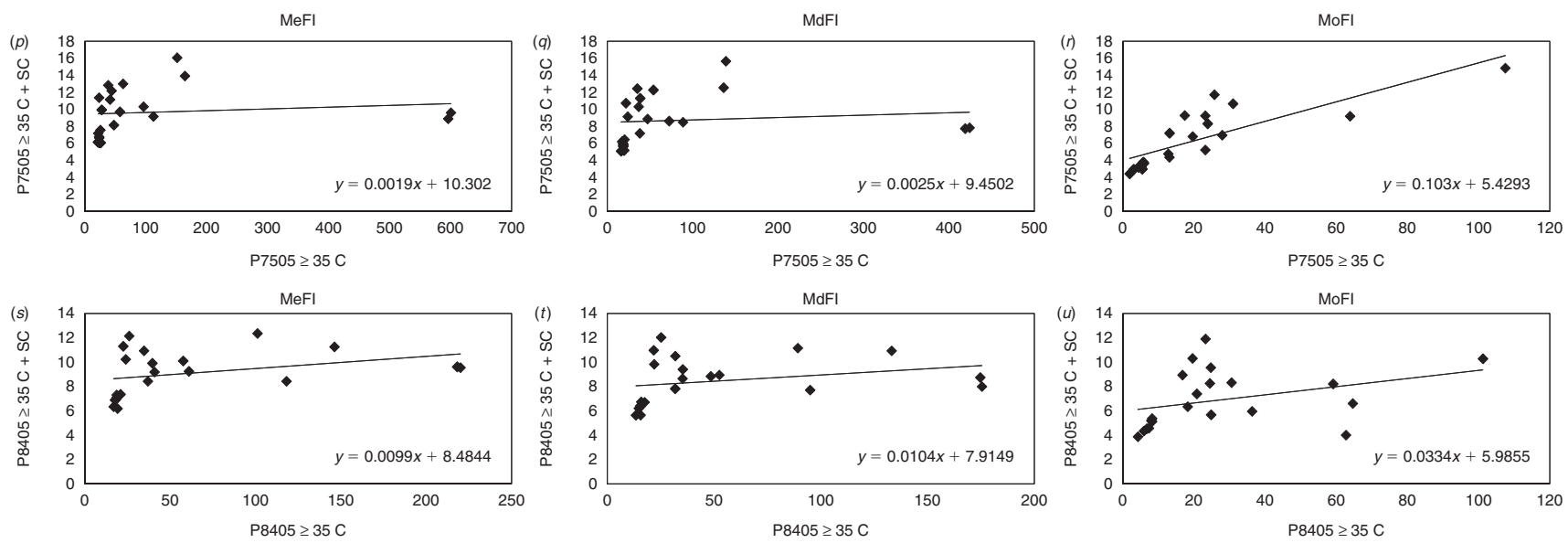

Fig. 3. Comparison of parameters $c$ and $b$ influence on the mean (MeFI), median (MdFI) and modal fire intervals (MoFI), to assess the effect of minimum mapping unit $(a-f)$, time series length $(g-l)$ and single-censored observations $(m-u)$. The solid line represents the adjustment between the various pairs of variables (the fitted equation is also shown); the perfect agreement is indicated by a dashed line $(a-l)$. 
Table 1. Main fire frequency descriptors for the 21 forest planning regions

AMI, Alto Minho; BMI, Baixo Minho; BAP, Barroso e Padrela; NDT, Nordeste; AMP, Área Metropolitana do Porto e Entre Douro e Vouga; TMG, Tâmega; DOU, Douro; CLI, Centro Litoral; DLA, Dão Lafões; BIN, Beira Interior Norte; PIN, Pinhal Interior Norte; PIS, Pinhal Interior Sul; BIS, Beira Interior Sul; OST, Oeste; RTJ- Ribatejo; AAL, Alto Alentejo; AML, Área Metropolitana de Lisboa; ACL, Alentejo Central; ALI, Alentejo Litoral; BAL, Baixo Alentejo; ALG, Algarve

\begin{tabular}{|c|c|c|c|c|c|c|}
\hline \multirow[t]{2}{*}{ Regions } & \multirow[t]{2}{*}{ Fire rotation period } & \multirow[t]{2}{*}{ Annual burnt area (\%) } & \multicolumn{4}{|c|}{ Fire return interval } \\
\hline & & & Mean & s.d. & Median & Mode \\
\hline AMI & 41 & 2.4 & 22.3 & 18.3 & 17.6 & 5.8 \\
\hline BMI & 73 & 1.4 & 26.3 & 23.9 & 19.5 & 3.1 \\
\hline BAP & 43 & 2.3 & 25.8 & 21.8 & 20.1 & 5.9 \\
\hline NDT & 113 & 0.9 & 48 & 39.5 & 38 & 12.8 \\
\hline AMP & 81 & 1.2 & 28 & 20 & 23.8 & 13.1 \\
\hline TMG & 37 & 2.7 & 22 & 20.4 & 16.1 & 2 \\
\hline DOU & 40 & 2.5 & 24.5 & 21.3 & 18.7 & 4.4 \\
\hline CLI & 137 & 0.7 & 57.9 & 45.2 & 47.1 & 19.6 \\
\hline DLA & 41 & 2.4 & 23.8 & 19.9 & 18.6 & 5.7 \\
\hline BIN & 32 & 3.1 & 24 & 20.4 & 18.7 & 5.2 \\
\hline PIN & 31 & 3.2 & 23.7 & 13.3 & 21.8 & 17.4 \\
\hline PIS & 31 & 3.2 & 38.8 & 23.5 & 35 & 25.7 \\
\hline BIS & 118 & 0.8 & 96.6 & 87.3 & 72.4 & 13.1 \\
\hline OST & 420 & 0.2 & 41.7 & 27.5 & 36.6 & 23.8 \\
\hline RTJ & 118 & 0.8 & 44.4 & 30.4 & 38.4 & 23.2 \\
\hline AAL & 169 & 0.6 & 164.5 & 124 & 136.1 & 63.9 \\
\hline AML & 481 & 0.2 & 112.8 & 93.6 & 88.7 & 28 \\
\hline ACL & 631 & 0.2 & 600.2 & 593.9 & 418.9 & 5.5 \\
\hline ALI & 553 & 0.2 & 151.6 & 88.1 & 138.8 & 107.4 \\
\hline BAL & 762 & 0.1 & 595.8 & 572 & 424.1 & 23.2 \\
\hline ALG & 106 & 0.9 & 63 & 44.1 & 53.9 & 31 \\
\hline Portugal & 82 & 1.2 & 36 & 31.1 & 27.6 & 6.7 \\
\hline
\end{tabular}

independent from fuel patch age. Confidence intervals for parameter $b$ were also generally narrow, with the exception of ACL $(477.3,760.3)$ and BAL $(517.4,705.5)$, where fires were few and typically small.

Fig. 5 shows a classification of the 21 forest planning regions into four groups. Segmentation thresholds (low-high) were defined on the basis of parameters $c$ and $b$ mean values for the 21 regions (1.3 for $c$ and 107.8 for $b$ ). High $c$-low $b$ regions, which display relatively high burning probability dependence on time since last fire and a relatively short fire recurrence interval, are mainly located in central-western Portugal. The only two high $c$-high $b$ regions are located in the southern half of the country. Most of the northern half of Portugal is characterised by low $c$-low $b$ values, i.e. low burning probability dependence on fuel age and a short fire recurrence interval. Finally, regions with low fire hazard dependence on fuel age and long fire recurrence periods (low $c$-high $b$ ) predominate in southern Portugal.

\section{Hazard functions}

Fig. 6 shows two hazard of burning $(\lambda)$ groups, well separated throughout the analysis period except for regions AMP (Área Metropolitana do Porto e Entre Douro e Vouga) and PIN, which start out at the lower burning probability values group and end up at the higher $\lambda$ group (PIN exceeds it) because of their high age dependence of burning probability. At age 31, burning probability of the lower and higher groups ranges from 0.002 to 0.031 and from 0.041 to 0.054 respectively. The top group includes, from higher to lower values at age 31, regions AMI, TMG, DLA, BIN, DOU, AMP, BAP and BMI (Baixo Minho). The bottom group includes, also in decreasing order of $\lambda$ at age 31, PIS, OST, RTJ (Ribatejo), NDT (Nordeste), CLI (Centro Litoral), ALG, BIS, AML, AAL, ALI, ACL and BAL. Region PIN shows the highest burning probability dependence on fuel age. It has one of the lowest $\lambda$ values at age $1(0.004)$, but by age 18 it has the highest value (0.05) and increases to 0.078 at age 31 . AMI displays the second highest $\lambda$ at the end of the study period (0.054). TMG has the highest $\lambda$ at age $1(0.039)$, which then grows very slowly with age, reaching 0.049 at age 31 . AMP and PIS also show a steep burning probability response to age. The bottom four functions (AAL, ACL, ALI and BAL) show that burning probability in the Alentejo regions is essentially independent of fuel age.

\section{Discussion}

From a methodological standpoint, our findings show that ignoring small fires has little or no effect on the estimates of Weibull function parameters because small fires, although numerous, typically represent a small fraction of the total area burnt. This finding is likely to apply to other fire regimes with very unequal fire size distributions. The length of the time series of burnt area maps does affect parameter estimates, such that using a longer time series leads to an estimation of longer fire cycles and lower hazard of burning dependence on fuel age. The length of the larger time series used in this study is in the range of fire rotation period for Mediterranean ecosystems (Chandler 
(a)

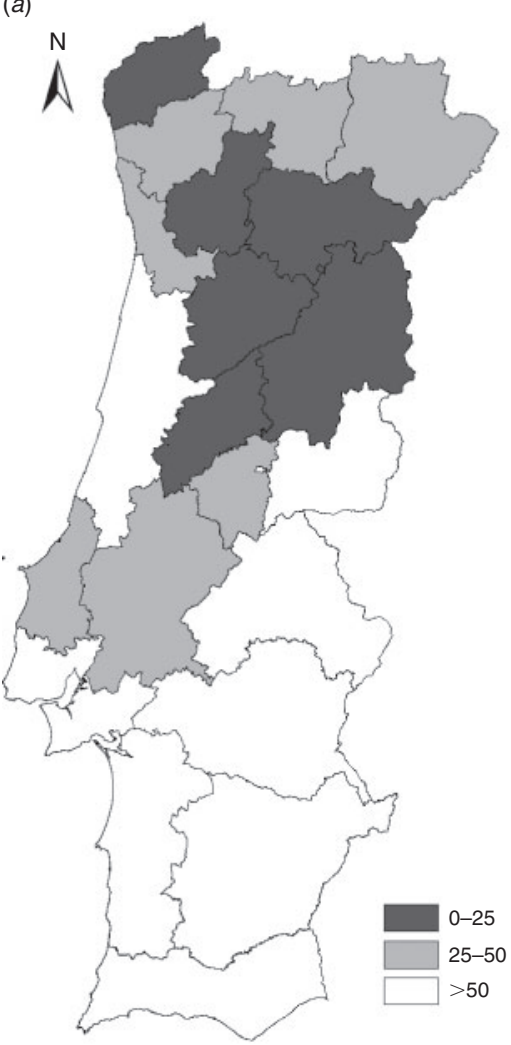

(b)

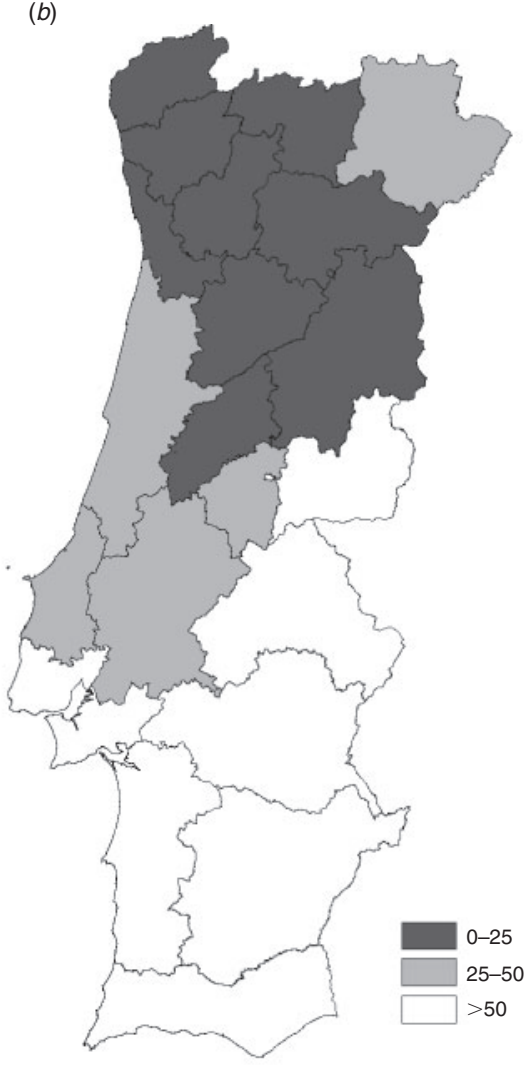

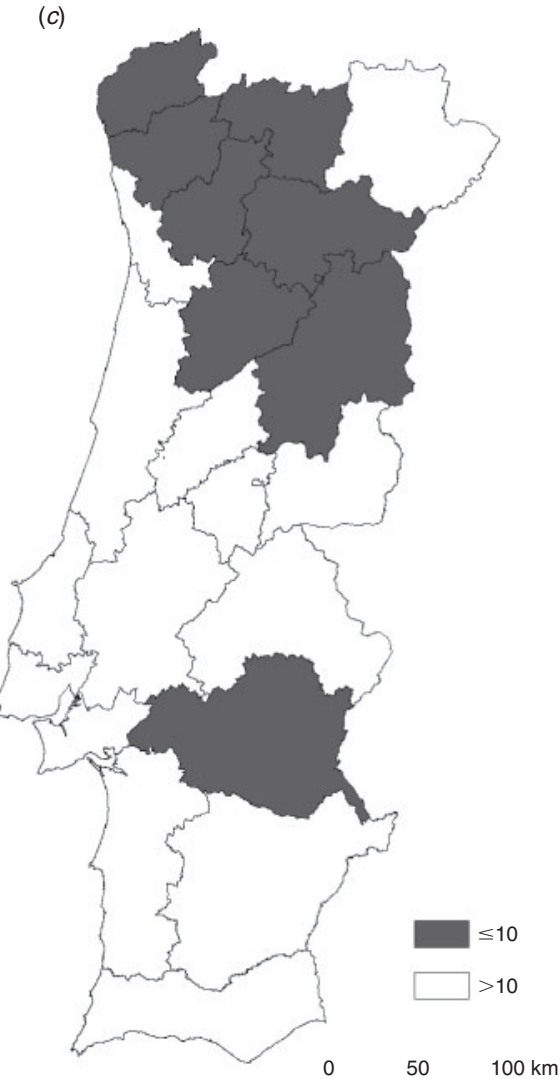

Fig. 4. Classes of $(a)$ mean, $(b)$ median and $(c)$ modal fire intervals (years).

et al. 1983; Schultz 2005) and observed in the most fire prone regions of Portugal. Therefore, the Weibull function parameter estimates obtained using the longer time series were considered more reliable than those obtained using the shorter series. We do not know how those parameter estimates would change if calculated with an even longer time series, but that is not an option using remote sensing, as high spatial resolution satellite imagery datasets currently span $<4$ decades. The difference in length between the two time series is too short to allow for the observed effect to be attributable to significant changes in fire regime, which are mainly determined by relatively slow changing (i.e. multi-decadal) variables, such as climate, land cover and demographics. Similar analyses in ecosystems such as tropical savannas, which display much shorter fire rotation periods than temperate ecosystems, ought to allow for assessment of changes in parameter estimates between time series spanning several times the fire rotation period.

Inclusion of SC fire intervals in the analysis has, by far, the strongest effect on parameter estimates (in agreement with Polakow and Dunne 1999 and Moritz et al. 2009), an effect that increases with fire rotation period and is important as most available studies have relied solely on complete fire interval data (Grissino-Mayer 1999; Lloret and Marí 2001; Vázquez and Moreno 2001; Díaz-Delgado et al. 2004; Fisher et al. 2009; Kraaij 2010). Our results show that exclusion of SC data leads to overestimation of fire frequency and hazard of burning dependence on fuel age. Again, in ecosystems with a very high fire frequency, consideration of SC fire intervals is likely to be less important, as these data tend to represent a smaller fraction of the total burnt area than in temperate ecosystems, for a comparable length of time.

The fire rotation period for Portugal was estimated at 82 years, corresponding to an annual percent of area burnt of $1.2 \%$. At PIN, PIS and BIN fire rotation period was low (31-32 years), matching the length of the time series used in our analysis. The eight regions with fire rotation period $\leq 43$ years, corresponding to an annual percentage of area burnt of $\geq 2.3 \%$ (AMI, BAP, TMG, DOU, DLA, BIN, PIN and PIS), account for $67 \%$ of the total area burnt during the study period. Use of a time series approximating the length of the fire rotation period implies that most of the area susceptible to fire will have burnt at least once, thus, minimising the drawbacks of disregarding double-censored data. The percentage of the region covered by forests and shrublands ranged from $\sim 50 \%$ at BAP and DOU to more than $75 \%$ at PIN and PIS. In the regions covered predominantly by forests, there were not many fires but fires were large (PIS and PIN), whereas more frequent but smaller fires characterised the fire regime in the shrubland dominated regions (DOU and BIN). Shrublands were burnt often to keep the vegetation palatable for sheep and goat herding. The lower annual percentage of area burnt $(0.1-0.2 \%)$ were found at OST, AML, ACL, ALI and $\mathrm{BAL}$, in central western and in southern Portugal, which are predominantly agricultural regions where fire is used mainly for crop residue burning. 


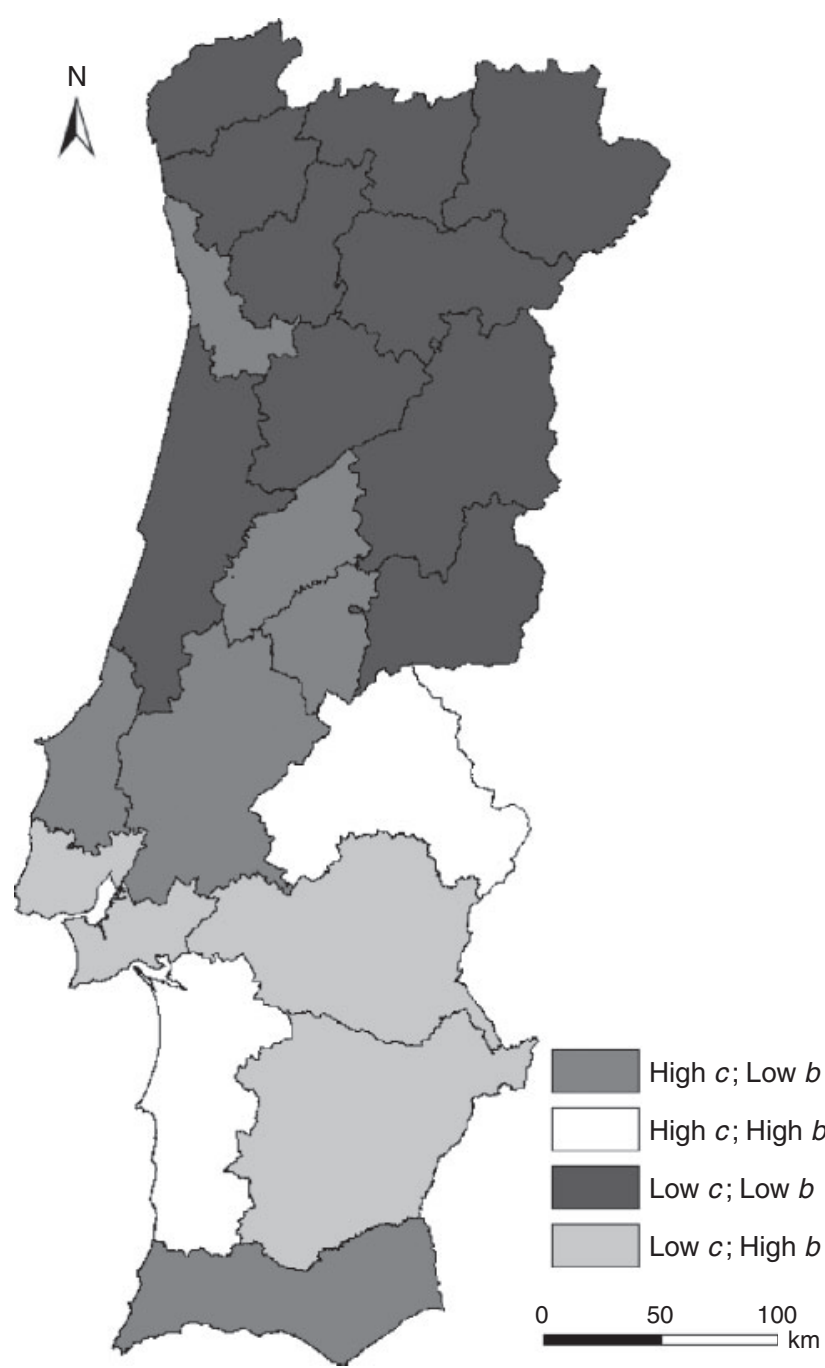

Fig. 5. Classification of the forest planning regions into four groups according to their values of $c$ and $b$.

Moreno et al. (1998) estimated that a fire rotation period $\leq 100$ years occurred in $\sim 22 \%$ Spain during the period 1974 1994. A fire rotation period of 64 years was reported by Vázquez and Moreno (2001) for a study area dominated by pine woodlands, also in Spain, which is about twice as long as that observed in the extensive pine forests of central Portugal. Díaz-Delgado et al. (2004) estimated a fire rotation period of 133 years for Catalonia, in north western Spain, a region covered mainly by forest and shrublands. Again, this is much longer than the 30-40 years we have estimated here for Portuguese regions with comparable land cover. Kraaij (2010) obtained a fire rotation period of 7.2 years for a fynbos area in South Africa, which is very short when compared to the fire rotation period of shrubland regimes in Portugal, and even short when compared with other fynbos.

Analysis of the geography of Weibull function parameters showed that six of the eight regions with annual percentage of area burnt $>2 \%$ displayed low $c$ and low $b$ values. A short fire return interval coupled with low burning probability dependence on fuel age was associated with frequent shrubland burning, as mentioned above. The remaining two high annual percentage of area burnt regions are classified as high $c-$ low $b$ and were the most extensively forested in the country. However, recent national forest inventory data show that the high wildfire frequency of the last 3 decades has led to the loss of large areas of maritime pine forests, which have been replaced by shrublands (AFN 2010). In some of these areas, high fire frequency may already have depleted the maritime pine canopy seed bank, leading to replacement of the forest by shrublands (Pereira et al. 2006). The other regions also in the high $c-$ low $b$ class are quite heterogeneous in terms of land cover, but shrublands represent a small fraction of their area, with the exception of ALG. The regions of southern Portugal, again with the exception of ALG, display high $b$ values, whereas $c$ values vary. Where evergreen oak woodlands were more extensive (AAL and ALI) fire incidence was more dependent on fuel age (high $c$ ), as is usual in land use regimes where fire is undesirable. At ACL and BAL the use of fire for annual crop residue burning was independent of fuel age (low $c)$.

Various authors have reported Weibull function parameter estimates for Mediterranean type regions. However, most of these studies do not report whether censored data were considered and may not be comparable with our results. O'Donnell et al. (2010) studied fire return intervals in semi-arid southern Western Australia. The fire regime in shrublands showed moderate age dependency $(c=2.47 ; b=47)$, in mallee (multi-stemmed low trees) some age dependency $(c=2.19 ; b=63)$ and in woodlands fire regimes were weakly dependent on fuel age $(c=1.37$; $b=414$ ). Values of parameter $c$ were greater than those we obtained for Portugal, suggesting a greater dependency on fuel age. Polakow and Dunne (1999) modelled the fire return interval regime in the Cape of God Hope Nature Reserve, South Africa, dominated by fire prone shrublands. They obtained values of $c=1.92$ and $b=788$, interpreted as an increase in the hazard of burning over time and a long fire cycle. All study areas by Moritz et al. (2004) showed minimal increases in the hazard of burning over time $(0.79 \leq c<2.06)$, except for one region that exhibited a marked burning probability increase as fuels got older $(c=3.33$ ); scale parameter $b$ ranged between 29.4 and 62.9. The higher $c$ and higher $b$ values obtained in these studies, compared with our own results in the present study probably reflect an absence of the frequent, intentional burning associated with sheep and goat herding that is relatively common in Portugal.

The mean, median and modal fire interval maps (Fig. 4) essentially reiterate the results obtained with the fire rotation period and the $b$ parameter of the Weibull model, showing a clear dichotomy between northern and southern Portugal. Throughout the regions with mean or median fire intervals $\leq 25$ years, the sustainability of maritime pine forests, managed for timber on a 35-40-year harvest cycle, is threatened. In recent decades many landowners under pressure from fire risk have converted pine plantations to eucalypt plantations that are managed for pulpwood under a short rotation of 9-12 years (Pereira et al. 2006). Díaz-Delgado et al. (2004) estimated mean fire intervals of 3.6 and 5.5 years in Catalonia, for two different grid sample sizes. These are low values for the mean fire interval considering that the fire rotation period obtained in the same study is 133 years. Such discrepancies are likely to result from the exclusion of censored data from the analyses. 


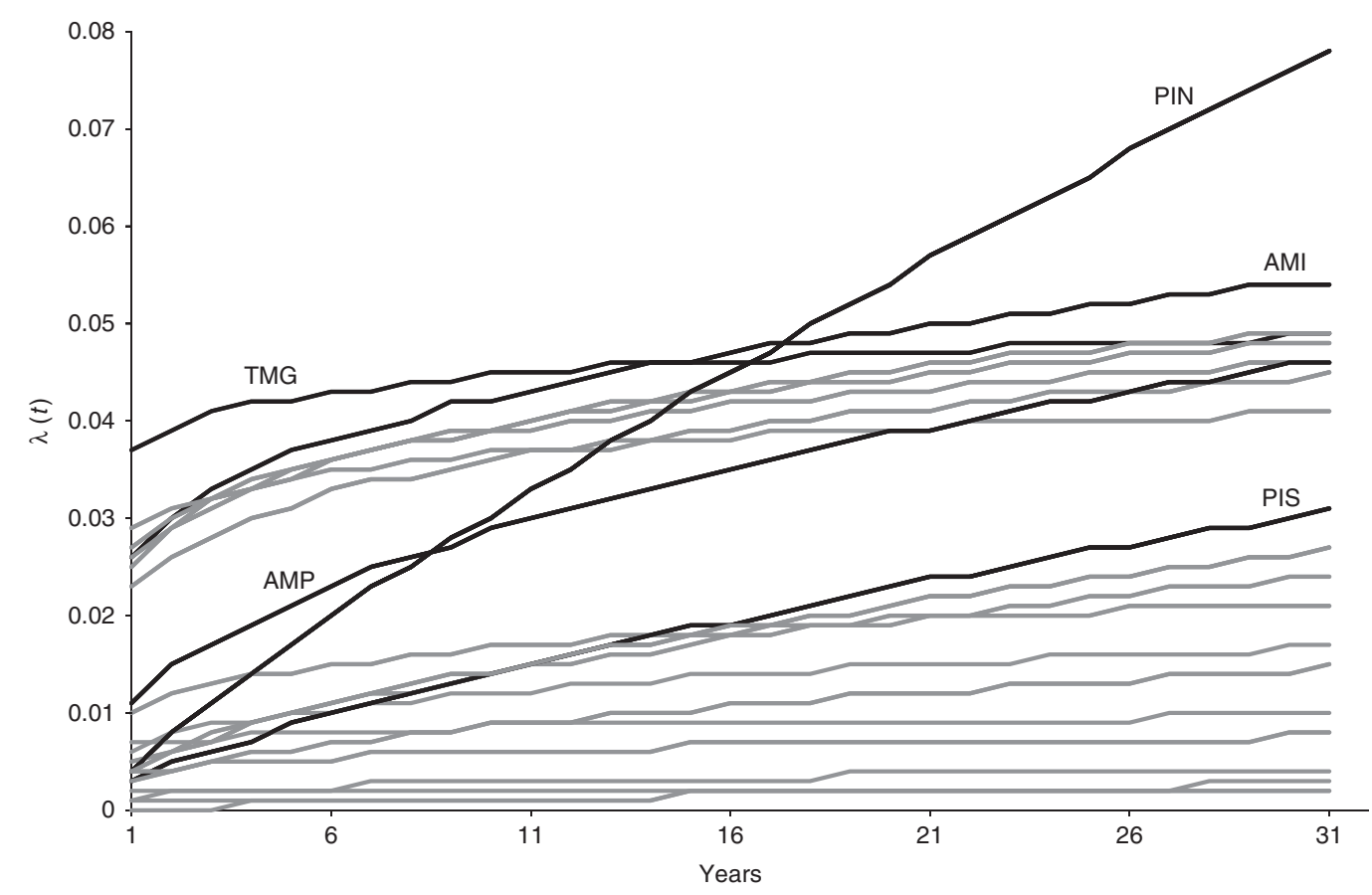

Fig. 6. Hazard of burning by forest planning region. Labelled curves illustrate distinctive hazard patterns.

\section{Conclusion}

Previous fire frequency analyses that disregard censored fire return intervals overestimate the increase in burning probability with fuel age and underestimate the characteristic life, or typical age at burn, of vegetation patches. These effects are more pronounced when estimates are obtained with time series that are short relative to the fire rotation period of the study area. Ignoring censored data implies loss of important information. In Portugal, fire frequency is high and burning probability dependence on fuel age is low in regions with large portions of shrubland. Fire frequency is lower and burning probability increase with time since fire is higher in extensively forested regions. Agricultural regions where crop residue burning is practiced display very low fire frequency and fire independence from fuel age. The fire regime observed in Portugal over the last 3 decades has led to a substantial decrease in the area of maritime pine forests, with a corresponding increase in the areas of shorter rotation eucalypt stands and of post-fire successional shrublands.

\section{Acknowledgments}

This research was funded by Fundação para a Ciência e Tecnologia, project 'Spatio-temporal fire patterns in Portugal (1984-2003). Impacts, risk assessment and fuel dynamics' (POCTI/AGG/44942/2002), coordinated by Maria José Vasconcelos (Tropical Research Institute, IICT), to whom the authors express their gratitude. JMCP participated under the scope of project 'Forest fires under climate, social and economic changes in Europe, the Mediterranean and other fire-affected areas of the world' (FUME), grant agreement 243888, funded by the European Commission.

\section{References}

Abaimov SG, Turcotte DL, Shcherbakov R, Rundle JB (2007) Recurrence and interoccurrence behaviour of self organised complex phenomena.
Nonlinear Processes in Geophysics 14, 455-464. doi:10.5194/NPG-14455-2007

AFN (2010) 'National forest inventory of mainland Portugal (2005-2006).' (Autoridade Florestal Nacional: Lisbon, Portugal) [in Portuguese]

Agee JK (1993) 'Fire ecology of Pacific Northwest forests.' (Island Press: Washington, DC)

Caetano M, Nunes V, Nunes A (2009) CORINE land cover 2006 for continental Portugal. Relatório Técnico, Instituto Geográfico Português. (Lisbon, Portugal)

Chandler C, Cheney P, Thomas P, Trabaut L, Williams D (1983) 'Fire in forestry. Vol 1. Forest behaviour and effects.' (Wiley: New York)

Díaz-Delgado R, Lloret F, Pons X (2004) Statistical analysis of fire frequency models for Catalonia (NE Spain, 1975-1998) based on fire scar maps from Landsat MSS data. International Journal of Wildland Fire 13, 89-99. doi:10.1071/WF02051

Dodson B (2006) 'The Weibull analysis handbook.' 2nd edn. (ASQ Quality Press: Milwaukee, WI)

European Commission (2006) Forest fires in Europe 2005. European Commission, Directorate-General Joint Research Centre, Report 6. (Luxembourg) Available at www.pedz.uni-mannheim.de/daten/edzbn/gdu/06/EUR_22312_EN.pdf [Verified 11 October 2011]

Fisher JL, Loneragan WA, Dixon K, Delaney J, Veneklaas EJ (2009) Altered vegetation structure and composition linked to fire frequency and plant invasion in a biodiverse woodland. Biological Conservation 142, 2270-2281. doi:10.1016/J.BIOCON.2009.05.001

Grissino-Mayer HD (1999) Modelling fire interval data from the American southwest with the Weibull distribution. International Journal of Wildland Fire 9(1), 37-50. doi:10.1071/WF99004

Heinselman ML (1973) Fire in the virgin forests of the Boundary Waters Canoe area, Minnesota. Quaternary Research 3, 329-382. doi:10.1016/ 0033-5894(73)90003-3

Heyerdahl EK, Agee JK (1996) Historical fire regimes of four sites in the Blue Mountains, Oregon and Washington. (University of Washington: Seattle, WA)

Johnson EA (1992) 'Fire and vegetation dynamics: studies from the North American boreal forest.' (Cambridge University Press: New York) 
Johnson EA, Gutsell SL (1994) Fire frequency models. Methods and interpretations. Advances in Ecological Research 25, 239-287. doi: 10.1016/S0065-2504(08)60216-0

Kraaij T (2010) Changing the fire management regime in the renosterveld and lowland fynbos of the Bontebok National Park. South African Journal of Botany 76, 550-557. doi:10.1016/J.SAJB.2010.04.008

Lepart J, Debussche M (1992) Human impact on landscape patterning: Mediterranean examples. In 'Landscape boundaries: consequences for biotic diversity and ecological flows'. (Eds AJ Hansen, F di Castri). (Springer-Verlag: New York)

Lloret F, Marí G (2001) A comparison of the medieval and the current fire regimes in managed pine forests of Catalonia (NE Spain). Forest Ecology and Management 141, 155-163. doi:10.1016/S0378-1127(00) 00323-6

Mather AS, Pereira JMC (2006) Transição Florestal e Fogo em Portugal. In 'Incêndios Florestais em Portugal'. (Eds JS Pereira, JMC Pereira, FC Rego, JMN Silva, TP Silva) pp. 257-286. (ISA Press: Lisbon, Portugal)

McCarthy MA, Gill AM, Bradstock RA (2001) Theoretical fire-interval distributions. International Journal of Wildland Fire 10, 73-77. doi:10.1071/WF01013

Miranda P, Coelho FES, Tomé AR, Valente MA, Carvalho A, Pires C, Pires HO, Pires VC, Ramalho C (2006) 20th Century Portuguese climate and climate scenarios. In 'Alterações Climáticas em Portugal. Cenários, Impactos e Medidas de Adaptação - Projecto SIAM II'. (Eds FD Santos, P Miranda) pp. 23-84. (Gradiva: Lisbon, Portugal)

Moreno JM (1999) Forest fires: trends and implications in desertificationprone areas of Southern Europe. In 'Mediterranean Desertification: Research Results and Policy Implications: Proceedings of the International Conference, Vol. 1'29 October-1 November, Crete, Greece. (Eds P Balabanis, D Peter, A Ghazi, M Tsogas) European Commission, Directorate-General Research, EUR 19303, pp. 115-150. (Luxembourg)

Moreno JM, Vázquez A, Vélez R (1998) Recent history of forest fires in Spain. In 'Large forest fires'. (Ed. JM Moreno) pp. 133-158 (Backhuys: Leiden, the Netherlands)

Moritz MA (2003) Spatiotemporal analysis of controls on shrubland fire regimes: age dependency and fire hazard. Ecology 84(2), 351-361. doi:10.1890/0012-9658(2003)084[0351:SAOCOS]2.0.CO;2

Moritz MA, Keeley JE, Johnson EA, Shaffner AA (2004) Testing a basic assumption of shrubland fire management: how important is fuel age? Frontiers in Ecology and the Environment 2(2), 67-72. doi:10.1890/ 1540-9295(2004)002[0067:TABAOS]2.0.CO;2

Moritz MA, Moody TJ, Miles LJ, Smith MM, de Valpine P (2009) The fire frequency analysis branch of the pyrostatistics tree: sampling decisions and censoring in fire interval data. Environmental and Ecological Statistics 16, 271-289. doi:10.1007/S10651-007-0088-Y

Nunes MCS, Vasconcelos MJP, Pereira JMC, Dasgupta N, Alldredge RJ, Rego FC (2005) Land cover type and fire in Portugal: do fires burn land cover selectively? Landscape Ecology 20, 661-673. doi:10.1007/ S10980-005-0070-8

O’Donnell AJ, Boer MM, McCaw WL, Grierson PF (2010) Vegetation and landscape connectivity control wildfire intervals in unmanaged semiarid shrublands and woodlands in Australia. Journal of Biogeography 28, 37-48.

Oliveira SLJ (2008) Análise da frequência do fogo em Portugal Continental (1975-2005) com a distribuição de Weibull. MSc thesis, ISA, UTL, Lisbon, Portugal.

Pausas JG, Vallejo R (1999) The role of fire in European mediterranean ecosystems. In 'Remote sensing of large wildfires in the European Mediterranean basin'. (Ed. E Chuvieco) pp. 3-16. (Springer: Berlin)

Pereira JMC, Santos MTN (2003) 'Fire risk and burned area mapping in Portugal.' (Direcção-Geral das Florestas: Lisbon, Portugal)

Pereira JS, Correia AV, Correia AP, Branco M, Bugalho M, Caldeira MC, Cruz CS, Freitas H, Oliveira AC, Pereira JMC, Reis RM, Vasconcelos MJ (2002) Forests and biodiversity. In 'Climate change in Portugal. Scenarios, impacts and adaptation measures. SIAM Project'. (Eds FD Santos, K Forbes, R Moita) pp. 363-414. (Gradiva: Lisbon, Portugal)

Pereira MG, Trigo RM, DaCamara CC, Pereira JMC, Leite SM (2005) Synoptic patterns associated with large summer forest fires in Portugal. Agricultural and Forest Meteorology 129, 11-25. doi:10.1016/J.AGR FORMET.2004.12.007

Pereira JMC, Carreiras JMB, Silva JMN, Vasconcelos MJ (2006) Alguns conceitos básicos sobre os fogos rurais em Portugal. In 'Incêndios Florestais em Portugal'. (Eds JS Pereira, JMC Pereira, FC Rego, JMN Silva, TP Silva) pp. 133-161. (ISA Press: Lisbon, Portugal)

Polakow DA, Dunne TT (1999) Modelling fire-return interval T: stochasticity and censoring in the two-parameter Weibull model. Ecological Modelling 121, 79-102. doi:10.1016/S0304-3800(99)00074-5

Santos C, Leite A, Santos E, Pinho J (2005) A estratégia sectorial florestal num sistema de planeamento regional 5.o Congresso Florestal Nacional, Viseu, Portugal.

Schultz J (2005) 'The ecoregions of the world - the ecological divisions of the geosphere.' (Springer: Berlin)

Trigo RM, Pereira JMC, Pereira MG, Mota B, Calado TJ, DaCamara CC, Santo FE (2006) Atmosfheric conditions associated with the exceptional fire season of 2003 in Portugal. International Journal of Climatology 26, 1741-1757. doi:10.1002/JOC.1333

Turcotte DL, Abaimov SG, Shcherbakov R, Rundle JB (2007) Nonlinear dynamics of natural hazards. In 'Nonlinear dynamics in geosciences'. (Eds A Tsonis, J Elsner) pp. 557-580. (Springer: New York)

Vázquez A, Moreno JM (2001) Spatial distribution of forest fires in Sierra de Gredos (Central Spain). Forest Ecology and Management 147, 55-65. doi:10.1016/S0378-1127(00)00436-9 
Appendix. Parameters estimates $(c$ and $b)$ for region and time series

Abbreviations used: AMI, Alto Minho; BMI, Baixo Minho; BAP, Barroso e Padrela; NDT, Nordeste; AMP, Área Metropolitana do Porto e Entre Douro e Vouga; TMG, Tâmega; DOU, Douro; CLI, Centro Litoral; DLA, Dão Lafões; BIN, Beira Interior Norte; PIN, Pinhal Interior Norte; PIS, Pinhal Interior Sul; BIS, Beira Interior Sul; OST, Oeste; RTJ, Ribatejo; AAL, Alto Alentejo; AML, Área Metropolitana de Lisboa; ACL, Alentejo Central; ALI, Alentejo Litoral; BAL, Baixo Alentejo; ALG, Algarve

\begin{tabular}{|c|c|c|c|c|c|c|c|c|c|c|c|c|}
\hline \multirow[t]{3}{*}{ Regions } & \multicolumn{4}{|c|}{$\mathrm{P} 8405 \geq 5$ (1) } & \multicolumn{4}{|c|}{$\mathrm{P} 8405 \geq 35$ (2) } & \multicolumn{4}{|c|}{$\mathrm{P} 7505 \geq 35$ (3) } \\
\hline & \multicolumn{2}{|c|}{$\mathrm{C}$} & \multicolumn{2}{|c|}{$\mathrm{C}+\mathrm{SC}$} & \multicolumn{2}{|c|}{$\mathrm{C}$} & \multicolumn{2}{|c|}{$\mathrm{C}+\mathrm{SC}$} & \multicolumn{2}{|c|}{$\mathrm{C}$} & \multicolumn{2}{|c|}{$\mathrm{C}+\mathrm{SC}$} \\
\hline & $c$ & $b$ & $c$ & $b$ & $c$ & $b$ & $c$ & $b$ & $c$ & $b$ & $c$ & $b$ \\
\hline AMI & 1.79 & 7.88 & 1.36 & 18.92 & 1.84 & 8.23 & 1.39 & 20.57 & 1.64 & 9.26 & 1.22 & 23.75 \\
\hline BMI & 1.72 & 6.70 & 1.26 & 18.27 & 1.77 & 6.96 & 1.26 & 20.80 & 1.62 & 8.12 & 1.10 & 27.24 \\
\hline BAP & 1.75 & 8.13 & 1.34 & 21.59 & 1.76 & 8.27 & 1.34 & 22.95 & 1.58 & 9.61 & 1.19 & 27.36 \\
\hline AMP & 2.08 & 10.87 & 1.64 & 25.66 & 2.27 & 11.55 & 1.76 & 27.02 & 1.93 & 12.13 & 1.42 & 30.78 \\
\hline TMG & 1.61 & 6.86 & 1.22 & 16.44 & 1.61 & 7.09 & 1.21 & 18.07 & 1.52 & 8.16 & 1.08 & 22.67 \\
\hline DOU & 1.68 & 7.54 & 1.33 & 18.10 & 1.69 & 7.72 & 1.33 & 19.29 & 1.66 & 8.16 & 1.15 & 25.72 \\
\hline CLI & 1.99 & 10.35 & 1.47 & 43.85 & 2.02 & 10.38 & 1.47 & 45.18 & 1.88 & 11.89 & 1.29 & 62.57 \\
\hline DLA & 1.85 & 7.63 & 1.38 & 19.17 & 1.88 & 7.80 & 1.39 & 19.99 & 1.69 & 8.86 & 1.20 & 25.31 \\
\hline BIN & 1.66 & 7.78 & 1.34 & 19.60 & 1.67 & 7.93 & 1.34 & 20.35 & 1.61 & 8.69 & 1.18 & 25.44 \\
\hline PIN & 2.36 & 12.51 & 2.16 & 25.55 & 2.46 & 12.75 & 2.23 & 25.59 & 2.15 & 13.60 & 1.84 & 26.64 \\
\hline PIS & 2.92 & 13.48 & 2.29 & 29.36 & 3.02 & 13.60 & 2.35 & 29.40 & 2.55 & 15.02 & 1.70 & 43.43 \\
\hline OST & 1.78 & 10.27 & 1.42 & 50.37 & 2.11 & 11.20 & 1.62 & 44.28 & 1.96 & 13.35 & 1.55 & 46.36 \\
\hline RTJ & 2.19 & 12.11 & 1.74 & 38.70 & 2.27 & 12.35 & 1.79 & 39.06 & 1.99 & 14.40 & 1.49 & 49.18 \\
\hline AAL & 1.68 & 13.30 & 1.52 & 105.71 & 1.70 & 13.85 & 1.57 & 112.64 & 1.77 & 16.11 & 1.34 & 179.07 \\
\hline AML & 1.55 & 9.08 & 1.19 & 84.26 & 1.78 & 9.48 & 1.26 & 127.06 & 2.02 & 11.35 & 1.21 & 120.08 \\
\hline ACL & 1.34 & 10.06 & 1.20 & 251.05 & 1.37 & 10.45 & 1.24 & 235.73 & 1.38 & 11.45 & 1.01 & 602.37 \\
\hline ALI & 2.55 & 12.47 & 1.76 & 137.48 & 2.47 & 12.69 & 1.75 & 164.18 & 2.59 & 18.30 & 1.78 & 170.45 \\
\hline BAL & 1.66 & 10.58 & 1.24 & 227.64 & 1.74 & 10.80 & 1.25 & 234.14 & 1.70 & 11.00 & 1.04 & 604.20 \\
\hline ALG & 2.29 & 10.35 & 1.44 & 66.89 & 2.39 & 10.44 & 1.46 & 67.39 & 2.15 & 15.25 & 1.45 & 69.42 \\
\hline Portugal & 1.68 & 8.47 & 1.29 & 28.86 & 1.71 & 8.73 & 1.31 & 30.36 & 1.62 & 9.98 & 1.16 & 37.92 \\
\hline
\end{tabular}

